\title{
The impact of oleanolic and ursolic acid on corneal epithelial cells in vitro
}

\author{
Anna Matysik-Woźniak', Roman Paduch, ${ }^{1,2}$, Ryszard Maciejewski ${ }^{3}$, Anselm G. Jünemannn', Robert Rejdak1,5 \\ ${ }^{1}$ Department of General Ophthalmology, Medical University of Lublin, Lublin, Poland \\ ${ }^{2}$ Department of Virology and Immunology, Institute of Microbiology and Biotechnology, Maria Curie-Skłodowska University, Lublin, Poland \\ ${ }^{3}$ Department of Human Anatomy, Medical University of Lublin, Lublin, Poland \\ ${ }^{4}$ University Eye Hospital, Rostock, Germany \\ ${ }^{5}$ Medical Research Centre, Polish Academy of Science, Warsaw, Poland
}

\begin{abstract}
INTRODUCTION. Oleanolic (OA) and ursolic (UA) acids belong to the triterpene group widely present in plants. These compounds are recognised to have anti-inflammatory properties and thus are considered to be used in therapies as well as in cosmetic, natural health, or diet products.

AIM. The scientific hypothesis of our study was to show that OA and UA influence corneal epithelial cells cultured in vitro.

METHODS. Toxicity tests, based on MTT and Neutral Red (NR) uptake, measurement of nitric oxide (NOx) level, as well as analysis of metalloproteinases (MMP-2 and MMP-9) amount and activity were performed.

RESULTS. UA expressed significantly higher toxicity on cells than OA. At the lowest concentration applied $(5 \mu \mathrm{M})$, UA limited cellular metabolism and viability on average by $22 \%$ as compared to untreated control, while $25 \mu \mathrm{M}$ resulted in values lower than $10 \%$. On the other hand, OA at the highest $(100 \mu \mathrm{M})$ concentration limited cellular metabolism and viability by about $20 \%$. NOx level significantly increased when OA and UA were applied at concentrations of 25 and $100 \mu \mathrm{M}$, respectively. OA and UA had a stronger impact on the level of MMP-2 than MMP-9. OA and UA reduced MMP-2 and MMP-9 in the whole range of concentrations. Tested triterpenoids had no significant impact on MMP activity.

CONCLUSIONS. OA and UA have a different impact on human corneal epithelial cells. UA is toxic for corneal epithelial cells, while OA exhibits milder activity, which may be useful for further analysis in ocular pharmacology.
\end{abstract}

KEY WORDS: corneal epithelial cells, Episkin, metalloproteinases, nitric oxide, oleanolic acid, toxicity model, ursolic acid

Ophthalmol J 2016; Vol. 1, No. 4, 124-132

\section{INTRODUCTION}

Oleanolic acid (OA) and ursolic acid (UA) belong to the group of ubiquitous pentacyclic triterpenes, which are widely found in herbs, other medicinal plants, and food. These compounds exert many biological activities such as anti-inflammatory, anticancer, antioxidant, and antiallergic [1, 2]. In view of a wide variety of activities, they were also considered as suitable in ophthalmology in order to protect the eye surface against adverse effects of particular inflammations and allergies $[1,3]$. Some of the factors acting adversely may include matrix metalloproteinases (MMPs) or high levels of nitric oxide (NO).

MMPs are a family of proteinases extracellular matrix (ECM) both in physiological processes ena- 
bling tissue remodelling or its normal functioning, and in pathological processes leading to inflammation, tissue destruction or, in the case of cancer, to tumour invasion and metastasis. Specifically, MMP-2 and MMP-9 are gelatinases that degrade type IV collagen, the major structural component of the ECM [4]. These proteases were found to take part in many ocular disorders like retinopathy [5], cataract [6], uveitis [7], or generally atopic ocular diseases [8]. In turn, local micromolar NO concentrations may exert similar effects that are connected with inflammation and local tissue destruction. On the other hand, nanomolar quantities of NO take part in maintaining physiological homeostasis on the ocular surface. Generally, NO regulate numerous vascular functions in eye, which in turn have a significant impact on proper functioning of other ocular tissues [9].

The cornea surface is created by non-keratinised epithelial cells whose arrangement and stability are essential for proper vision. These cells are subjected to continuous renewal and any manipulation of this process as well as of homeostasis of the corneal layer may lead to substantial changes in visual acuity [10]. Any substances which are administered to the surface of the eye should be analyzed in terms of their impact not only on corneal epithelial cells viability but simultaneously on the induction of soluble factors release which may exert an adverse effect on corneal epithelial layer. Therefore, the influence of triterpenes on local alteration in MMPs or NO levels in the corneal epithelium was analysed due to their potential important impact on the functionality of this tissue, and consequently on proper vision.

In our study we hypothesised that OA or UA are compounds that might modify the viability of corneal epithelium and secretion of MMPs and NO by these cells in vitro. For this reason, we introduced an HCE three-dimensional model (SkinEthic $^{\text {TM }}$ from Episkin, Lyon, France) to test NOx and MMPs quantity and activity, as well as classic two-dimensional cultures of corneal epithelial cells in order to demonstrate changes in cell viability after their incubation with OA and UA.

\section{MATERIALS AND METHODS CELL CULTURES}

Human normal corneal epithelial cell line 10.014 pRSV-T (ATCC No. CRL-11515) was used. The cells were cultured as monolayers in $25-\mathrm{cm}^{2}$ culture flasks (Nunc, Roskilde, Denmark) coated with $\mathrm{PureCol}^{\mathrm{TM}}$ ultrapure collagen (INAMED Biomaterials, Fremont, CA) at $3.1 \mathrm{mg} / \mathrm{mL}$ concentration. The cell line was maintained in defined K-SFM (keratinocyte serum-free medium) (Gibco) supplemented with $75 \mu \mathrm{g} / \mathrm{mL}$ endothelial cell growth factor (Sigma), $0.05 \mathrm{mg} / \mathrm{mL}$ bovine pituitary extract (Gibco), $500 \mathrm{ng} / \mathrm{mL}$ hydrocortisone (Sigma), $0.0005 \mathrm{mg} / \mathrm{mL}$ bovine insulin (Gibco), and antibiotics $(100 \mathrm{U} / \mathrm{mL}$ penicillin, $100 \mu \mathrm{g} / \mathrm{mL}$ streptomycin) (Sigma, St Louis, MO) at $37^{\circ} \mathrm{C}$ in a humidified atmosphere with $5 \% \mathrm{CO}_{2}$. This cell culture was used for MTT and NR toxicity tests and MGG staining.

HCE three-dimensional model (SkinEthic ${ }^{\text {TM }}$ from Episkin, Lyon, France) commercially available was also used. This reconstructed HCE model consists of immortalised human corneal epithelial cells cultured on a chemically-defined permeable polycarbonate membrane insert at the air-liquid interface. The construct is a multi-layered, stratified epithelium similar to that of normal human corneal epithelium. This model represents 5-7 viable cell layers without significant histological abnormalities growing on a $0.5 \mathrm{~cm}^{2}$ surface area. These layers consist of columnar basal cells, transitional wing cells, and flattened superficial cells.

The tissues were shipped at room temperature in agarose gel that contained medium to preserve the quality of the tissues. This agarose-gel was used only for transportation, to keep high viability of cells. After delivery, the inserts with corneal tissue were immediately transferred to a new 24-well culture plate. Thereafter, a liquid-liquid interface was performed because a new culture medium was added both inside the wells of the 24-well plates (medium volume $0.6 \mathrm{~mL}$ ) as well as inside the inserts with cells (medium volume $0.15 \mathrm{~mL}$ ). Appropriate concentrations $(5 ; 10 ; 25 ; 50 ; 100 \mu \mathrm{M})$ of oleanolic acid (OA) and ursolic acid (UA) were added to the medium present in the insert. 24-well plates with inserts were incubated at $37^{\circ} \mathrm{C}, 5 \%$ $\mathrm{CO}_{2}$ in a humidified incubator. The medium from the wells, but not inserts, was collected 24 hours later. As a culture medium we used the original fluid that was delivered together with cells by the manufacturer. This model was used for NOx, MMP, and zymography analysis.

\section{NEUTRAL RED (NR) UPTAKE ASSAY}

NR cytotoxicity assay analyses the uptake and lysosomal accumulation of Neutral Red stain. Cells that are damaged do not accumulate the dye. 
Cells were grown in 96-well multiplates in $100 \mu \mathrm{L}$ of culture medium (K-SFM) with supplements and oleanolic acid (OA) (Sigma) or ursolic acid (UA) (Sigma) in the concentration range $5-100 \mu \mathrm{M}$ for 24 hours. Subsequently, the medium was discarded and $0.4 \%$ NR (Sigma) solution medium was added to each well. The plate was incubated for three hours at $37^{\circ} \mathrm{C}$ in a humidified $5 \% \mathrm{CO}_{2} / 95 \%$ air incubator. After incubation, the dye-containing medium was removed, cells fixed with $1 \% \mathrm{CaCl}_{2}$ in $4 \%$ paraformaldehyde, and thereafter the incorporated dye was solubilised using $1 \%$ acetic acetate in $50 \%$ ethanol solution $(100 \mu \mathrm{L})$. The plates were gently shaken for 20 minutes at room temperature and the extracted dye absorbance was measured spectrophotometrically at $540 \mathrm{~nm}$ using a microplate reader (Emax; Molecular Devices Corp., Menlo Park, CA).

\section{MTT ASSAY}

MTT assay is based on the conversion of yellow tetrazolium salt by viable cells to purple formazan crystals. Mitochondrial succinate dehydrogenase catalyses this reaction.

Cells were grown in 96-well multiplates in $100 \mu \mathrm{L}$ of culture medium with OA or UA addition at the appropriate concentration $(5-100 \mu \mathrm{M})$. After 24 hours of incubation, MTT solution $(5 \mathrm{mg} / \mathrm{mL}$, $25 \mu \mathrm{L} /$ well) (Sigma) was added, and incubation was conducted for a further three hours. The crystals of formazan were solubilised overnight in a $10 \%$ sodium dodecyl sulphate $0.01 \mathrm{M} \mathrm{HCl}$ mixture $(100 \mu \mathrm{L})$. The product was quantified spectrophotometrically by absorbance measurement at $570 \mathrm{~nm}$ wavelength using an Emax microplate reader (Molecular Devices Corp.).

\section{NO MEASUREMENT}

Nitrate, a stable end product of NO, was determined in culture supernatants by a spectrophotometric method based on the Griess reaction.

Corneal epithelial cells (EpiSkin HCE model) were incubated for 24 hors with OA and UA concentrations $(5 ; 10 ; 25 ; 50 ; 100 \mu \mathrm{M})$. Thereafter, culture supernatants were collected. The samples were frozen at $-80^{\circ} \mathrm{C}$ and stored for no longer than one month. $100 \mu \mathrm{L}$ of supernatant was plated in 96-well flat-bottomed plates in triplicate and incubated with $100 \mu \mathrm{L}$ of Griess reagent (1\% sulphanilamide/ $0.1 \% N$-(1-naphthyl)ethylenediamine dihydrochloride) (Sigma) in $3 \% \mathrm{H}_{3} \mathrm{PO}_{4}(\mathrm{POCH}$ Gliwice, Poland) at room temperature for $10 \mathrm{~min}$ utes. The optical density was measured at $570 \mathrm{~nm}$ using a microplate reader (Emax; Molecular Devices Corp.). A standard curve was achieved using $0.5-25 \mu \mathrm{M}$ sodium nitrite $\left(\mathrm{NaNO}_{2}\right)$ for calibration and quantitative analysis.

\section{MAY-GRÜNWALD-GIEMSA (MGG) STAINING}

Briefly, cells were fixed with methanol for 10 minutes and stained with May-Grünwald stain for three minutes, and diluted in an equal volume of distilled water for a further three minutes. The stain was removed and Giemsa stain diluted (1:20) in water was added for 20 minutes. After that time the dye was removed and slides were rinsed three times with distilled water, air dried, and observed under a light microscope (Olympus BX51).

\section{ZYMOGRAPHY}

MMP activity was measured using SDS-PAGE zymography.

Gelatine $(300 \mu \mathrm{g} / \mathrm{mL})$ (Sigma) was incorporated into a $7.5 \%$ polyacrylamide gel. Culture supernatant samples were mixed with equal volumes of $2 \times$ sample buffer $(0.25 \mathrm{M}$ Tris- $\mathrm{HCl} \mathrm{pH} 6.8$, $10 \%(\mathrm{v} / \mathrm{v})$ glycerol, $0.05 \%(\mathrm{w} / \mathrm{v})$ bromophenol blue, and 5\% (w/v) SDS) and separated by electrophoresis. The gel was washed in distilled water, incubated for one hour at room temperature with $2.5 \%(\mathrm{v} / \mathrm{v})$ Triton X-100, washed again in distilled water, and incubated for 24 hours at $37^{\circ} \mathrm{C}$ with developing buffer $(0.05 \mathrm{M}$ Tris- $\mathrm{HCl}, \mathrm{pH} 7.4,0.01 \mathrm{M}$ $\mathrm{CaCl}_{2}$ and $0.02 \%(\mathrm{w} / \mathrm{v}) \mathrm{NaN}_{3}$ ). After washing, the gel was stained for one hour with $0.2 \%$ Coomassie blue in $50 \%(\mathrm{v} / \mathrm{v})$ methanol and $10 \%(\mathrm{v} / \mathrm{v})$ acetic acid. Thereafter, the gel was de-stained with $20 \%$ $(\mathrm{v} / \mathrm{v})$ methanol and $10 \%(\mathrm{v} / \mathrm{v})$ acetic acid. Bands of digested substrate indicated metalloproteinase activity.

\section{MIMP-2 AND MIMP-9 ELISA ASSAY}

The levels of MMP-2 and IL-6 were tested immunoenzymatically (ELISA) using commercially available kits (R\&D, Minneapolis, MN, USA), according to the manufacturers' instructions.

Supernatant samples were added to 96-well microplates coated with monoclonal antibodies against human MMP-2 or MMP-9 and incubated for two hours at room temperature. After three washes in the appropriate buffer, polyclonal secondary antibodies conjugated to horseradish peroxidase were added and incubated for two hours at room temperature. The optical density was measured at $450 \mathrm{~nm}$ using a microplate reader (Molecular Devices Corp., 


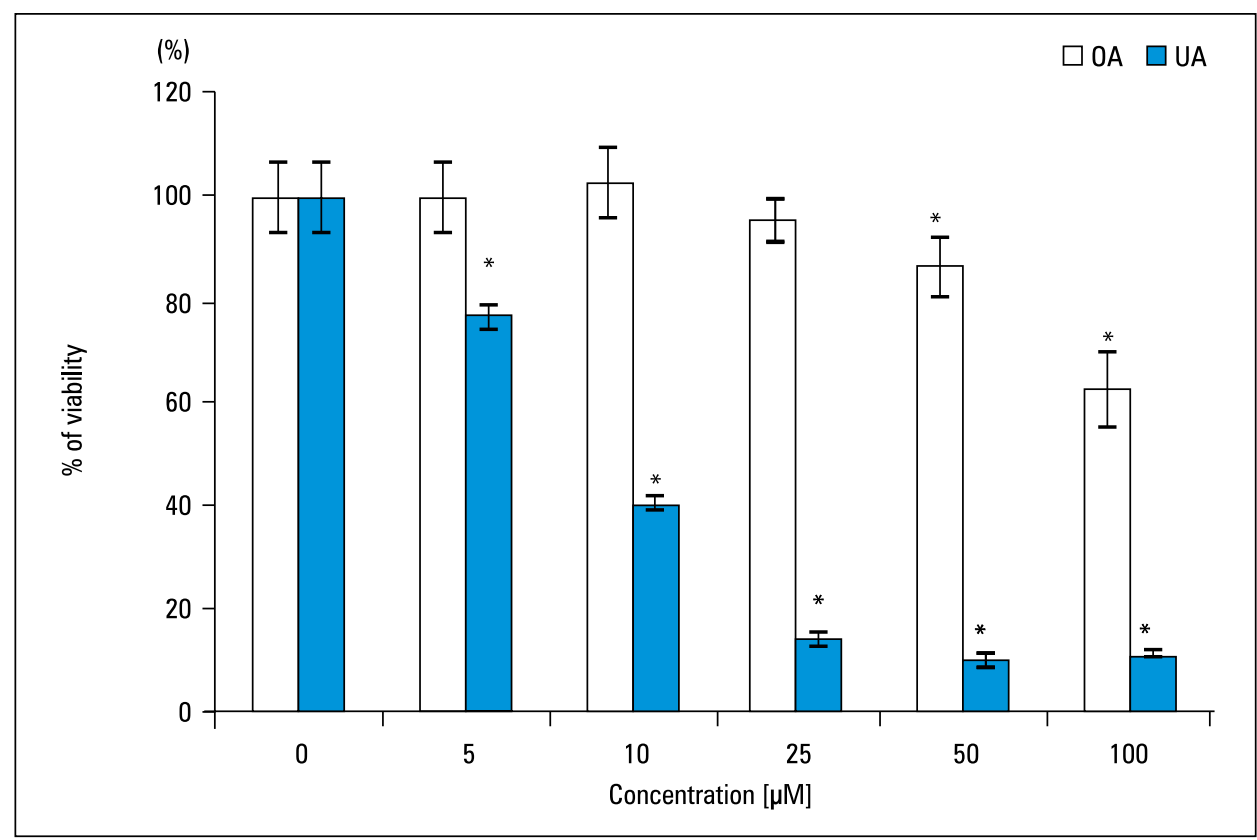

FIGURE 1. The effect of 24-hour treatment of human corneal epithelial cells with oleanolic acid (OA) and ursolic acid (UA). MTT assay. The results are presented as a percentage of the controls, arbitrarily set to $100 \%$. The figure shows an average of three independent experiments. ${ }^{*} p \leq 0.05$ - compared with the control

Emax, Menlo Park, CA, USA), and MMP-2 or MMP-9 concentrations were calculated from the standard curves prepared from recommended substrates. The sensitivity of tests was: $0.082 \mathrm{ng} / \mathrm{mL}$ for human MMP-2 and $0.156 \mathrm{ng} / \mathrm{mL}$ for human MMP-9.

\section{STATISTICAL ANALYSIS}

Results are presented as means \pm SD from three experiments. Data were analysed using one-way ANOVA analysis. Differences of $p \leq 0.05$ were considered significant.

\section{RESULTS}

Cytotoxic and metabolism changing activity (MTT and NR tests).

Oleanolic acid (OA) at concentrations higher than $50 \mu \mathrm{M}$ decreased metabolic activity of corneal epithelial cells. At $100 \mu \mathrm{M}$ of OA applied, it was $37 \% \pm 7 \%$ lower than control. Ursolic acid (UA) expressed stronger activity than OA and significantly limited metabolism of cells even at the lowest concentration $(5 \mu \mathrm{M})(23 \% \pm 2 \%)$ applied as compared to untreated controls. Concentrations of UA higher than $25 \mu \mathrm{M}$ decreased metabolism of corneal epithelial cells to the level lower than 10\% (Fig. 1).

Similar results were obtained when the cytotoxic activity of both compounds was tested using
NR uptake assay. However, OA significantly decreased cell viability only at the highest concentration $(100 \mu \mathrm{M})(18 \% \pm 3.5 \%)$ applied, as compared to controls. UA activity coincided with the results obtained in MTT test (Fig. 2).

Staining of cells with May-Grünwald-Giemsa (MGG) dye confirmed corneal epithelial cell sensitivity to UA and the low impact of OA on these cells (Fig. 3).

\section{NITRIC OXIDE (NOX) LEVEL}

Control level of NOx produced by corneal epithelial cells was $0.51 \pm 0.01 \mu \mathrm{M}$. Both OA and UA at concentrations lower than $10 \mu \mathrm{M}$ had no impact on NOx production by corneal epithelial cells as compared to controls. Starting form $25 \mu \mathrm{M}$ concentration, UA gradually increased the $\mathrm{NOx}$ level in culture medium. At the highest concentration used $(100 \mu \mathrm{M})$ it was $1.93 \pm 0.12 \mu \mathrm{M}$. On the other hand, OA only at the concentration of $100 \mu \mathrm{M}$ increased the NOx level to the value of $0.67 \pm 0.01 \mu \mathrm{M}$ (Fig. 4).

\section{OA AND UA IMPACT ON PRODUCTION OF METALLOPROTEINASES (MIMP=2 AND MIMP-9) \\ Metalloproteinase (MMP-2 and MMP-9) levels} were tested quantitatively by ELISA, and qualitative activity of enzymes was tested by zymography. The levels of both enzymes were very low. 


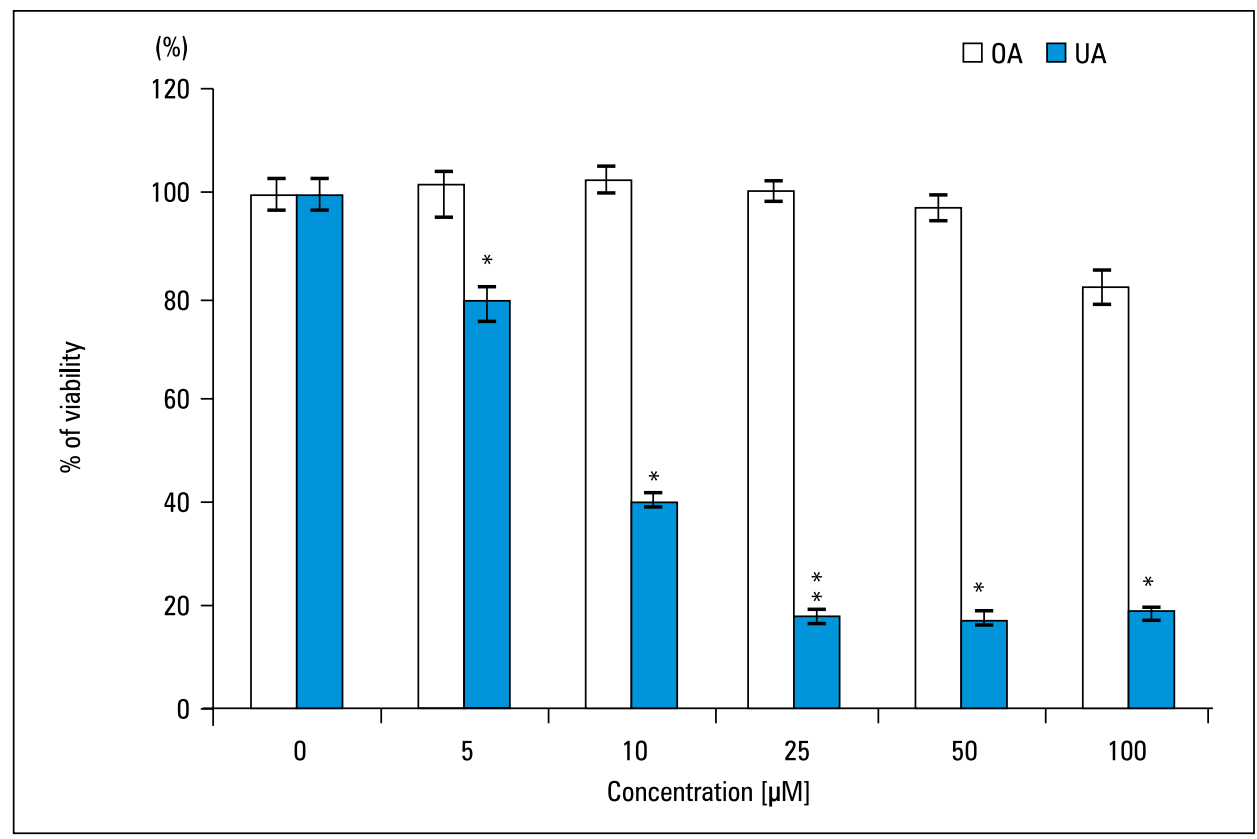

FIGURE 2. The effect of 24-hour treatment of human corneal epithelial cells with oleanolic acid (OA) and ursolic acid (UA). Neutral Red uptake assay. The results are presented as a percentage of the controls, arbitrarily set to $100 \%$. The figure shows an average of three independent experiments. ${ }^{*} p \leq 0.05-$ compared with the control
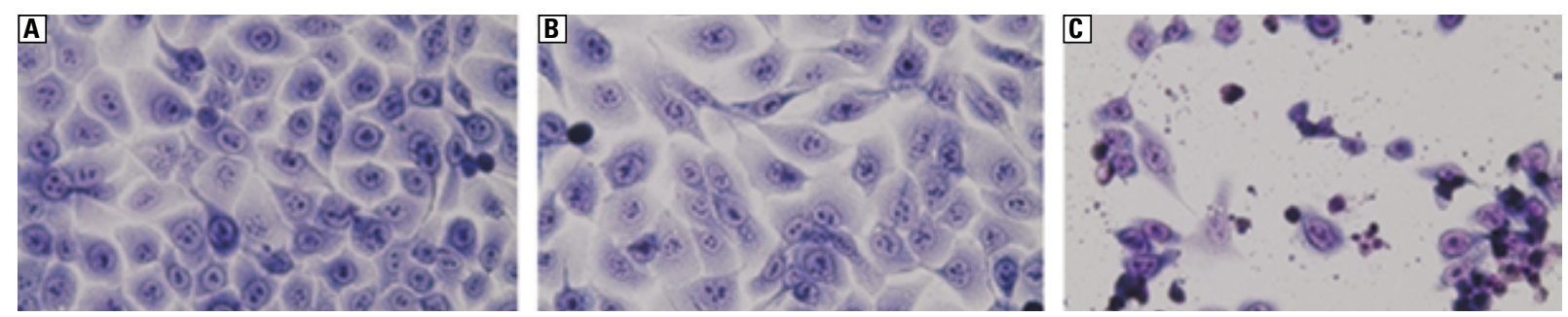

FIGURE 3. May-Grünwald-Giemsa (MGG) staining of corneal (pRSV-T) cells. Control cells (A), cells treated with oleanolic acid (OA) $(100 \mu \mathrm{M})(B)$, and treated with ursolic acid (UA) $(100 \mu \mathrm{M})(\mathrm{C})$ for 24 hours. Magnification $200 \times$. Bar $=20 \mathrm{~mm}$

The control amount of MMP-2 protein was $0.424 \mathrm{ng} / \mathrm{mL}$. The protein level was decreased when the whole range of OA concentrations was used. The most significant reductions, about three-times as compared to control, were observed when low concentrations of terpenes $(5-10 \mu \mathrm{M})$ were applied. UA similarly to OA decreased MMP-2 level in a concentration-dependent manner. At the highest concentrations of UA applied $(50 \mu \mathrm{M}$ and $100 \mu \mathrm{M})$ the decreased protein level reached values about $30 \%$ lower than those observed in controls (Fig. 5).

MMP-9 control amount was $0.572 \mathrm{ng} / \mathrm{ml}$. Application of OA and UA reduced the level of this protein. At the lowest concentration $(5 \mu \mathrm{M}) \mathrm{OA}$ reduced the MMP-2 level by half, while at its highest concentration $(100 \mu \mathrm{M})$ UA reduced this reading to about $40 \%$, as compared to controls (Fig. 6).
Zymography analysis revealed that enzymatic activity could be found only when the highest concentration $(100 \mu \mathrm{M})$ of both OA and UA was used. However, it was not possible to find separate bands of proteases or their pre-forms, but the whole slots after electrophoresis revealed low gelatine proteolytic activity (Fig. 7).

\section{DISCUSSION}

Natural compounds have been widely used to treat different human ailments. Among natural substances showing activity as health reinforcing stimuli, terpenes make up the most important group. Oleanolic (OA) and ursolic (UA) acids are members of pentacyclic triterpenes and are currently considered to have possible beneficial effects on ocular tissues. These compounds have already been shown 


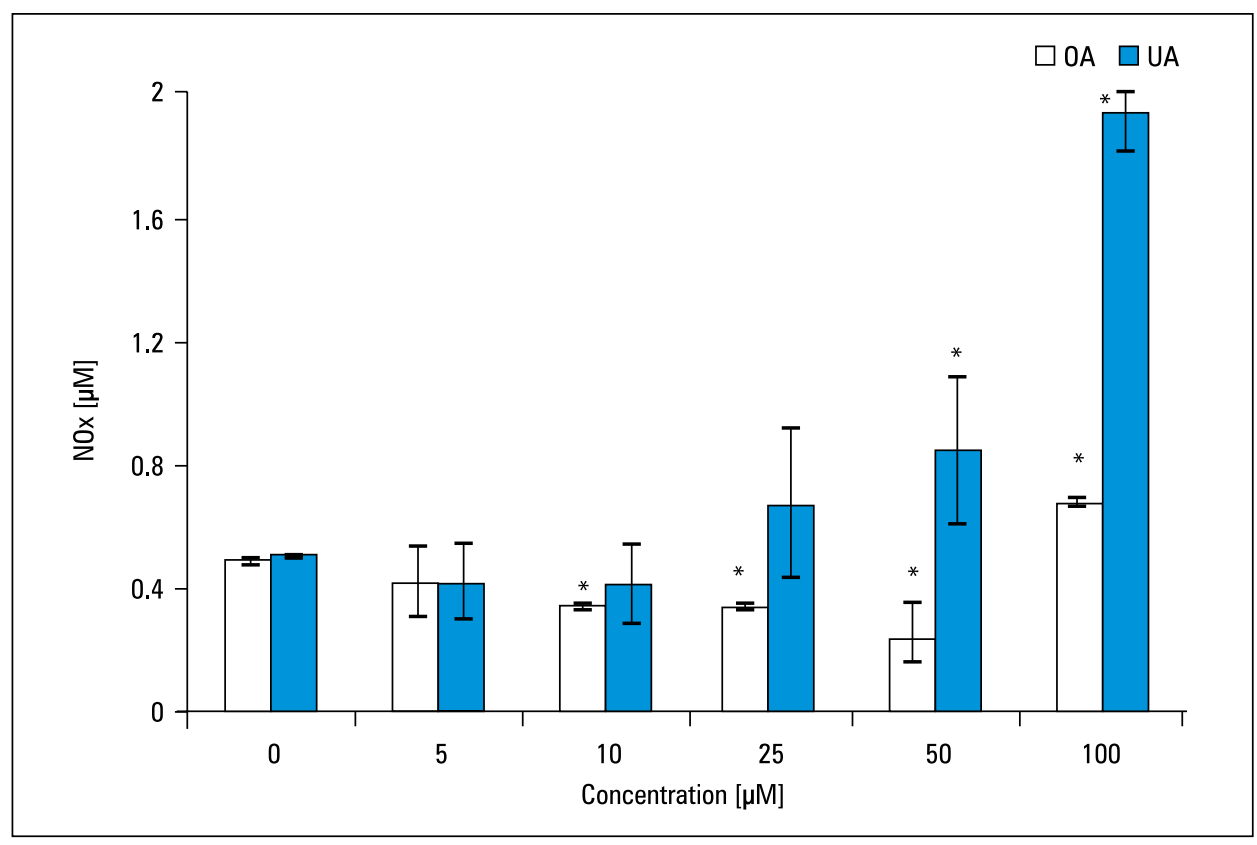

FIGURE 4. The effect of oleanolic (OA) and ursolic (UA) acid exerted on nitric oxide (NO) (nitrite and nitrate — NOx) secretion from human corneal epithelium in vitro. Incubation time -24 hours. The results are presented as mean \pm SD of three independent experiments. * $p \leq 0.05$ - compared with the respective control

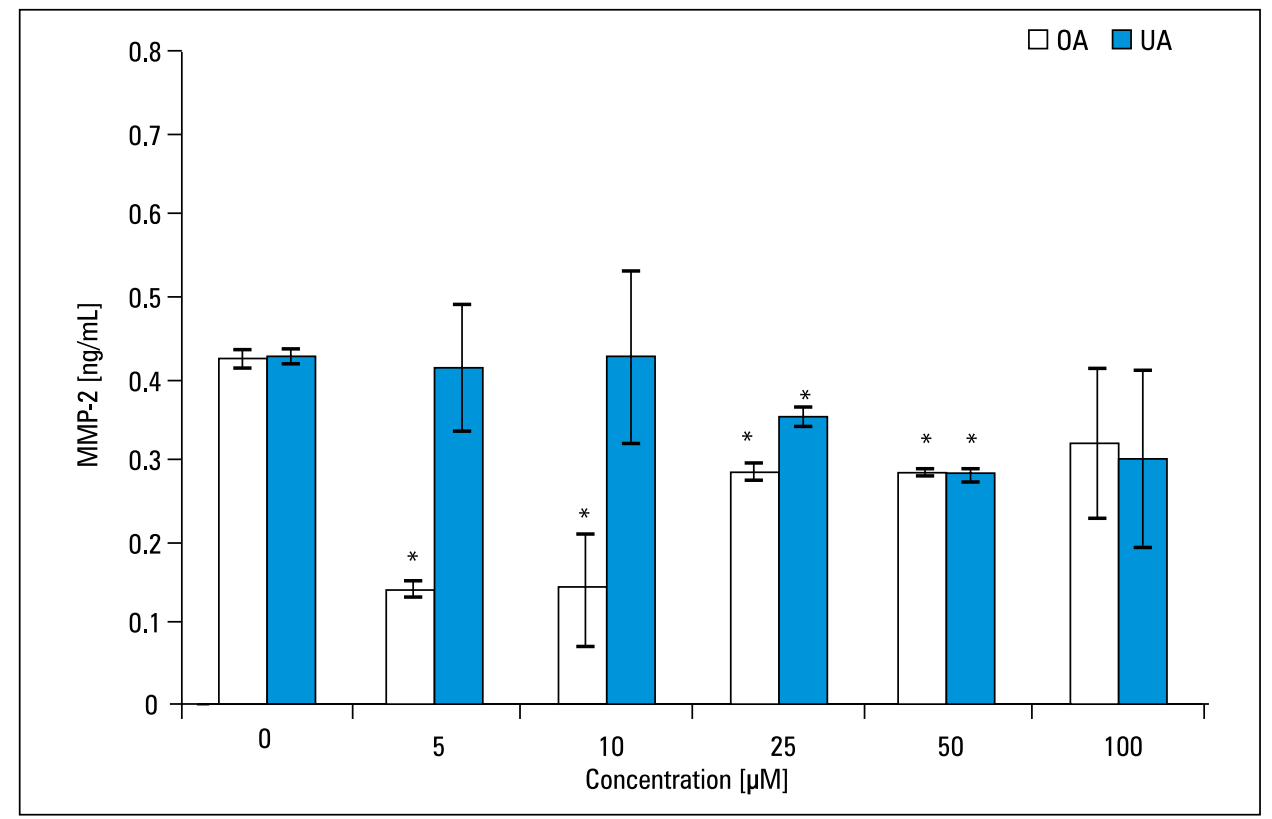

FIGURE 5. The effect of 24-hour treatment of human corneal epithelial cells with oleanolic acid (OA) and ursolic acid (UA). ELISA assay of MMP-2 level. The figure shows an average of three independent experiments. ${ }^{*} p \leq 0.05$ - compared with the control

to have antiallergic properties [3] as well as being useful when uploaded onto nanoplatforms in anti-inflammatory applications [1]. In our study we showed that, in principle, only oleanolic acid at concentrations lower than $50 \mu \mathrm{M}$ is not toxic for human corneal epithelial cells. On the other hand, ursolic acid significantly reduced the viability of cells even at the lowest $(5 \mu \mathrm{M})$ concentration used. These results are in agreement with literature data showing that UA modulates mitochondrial redox activity and decreases mitochondrial membrane potential; this results in cell cycle phase arrest and consequently apoptosis of cells $[11,12]$. Moreover, UA treatment of cells may decrease the anti-apop- 


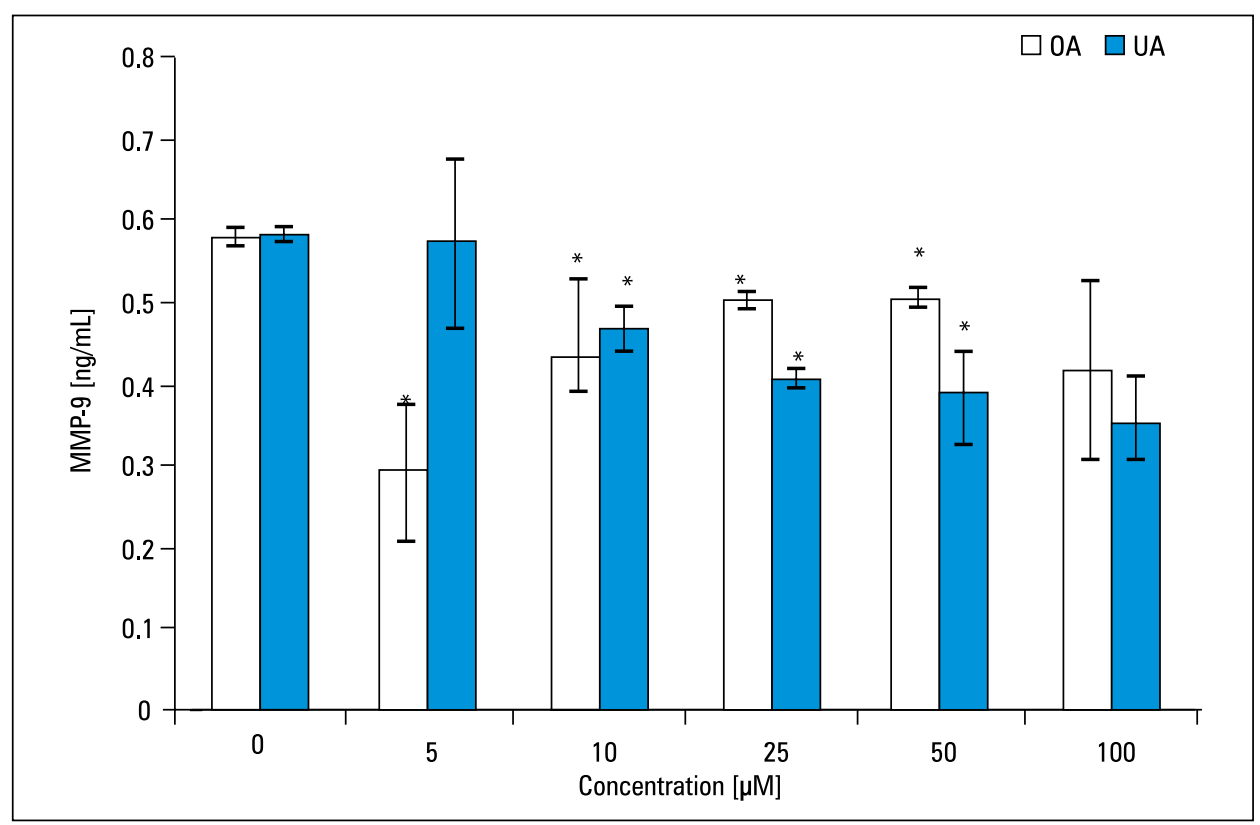

FIGURE 6. The effect of 24-hour treatment of human corneal epithelial cells with oleanolic acid (OA) and ursolic acid (UA). ELISA assay of MMP-9 level. The figure shows an average of three independent experiments. ${ }^{*} p \leq 0.05-$ compared with the control

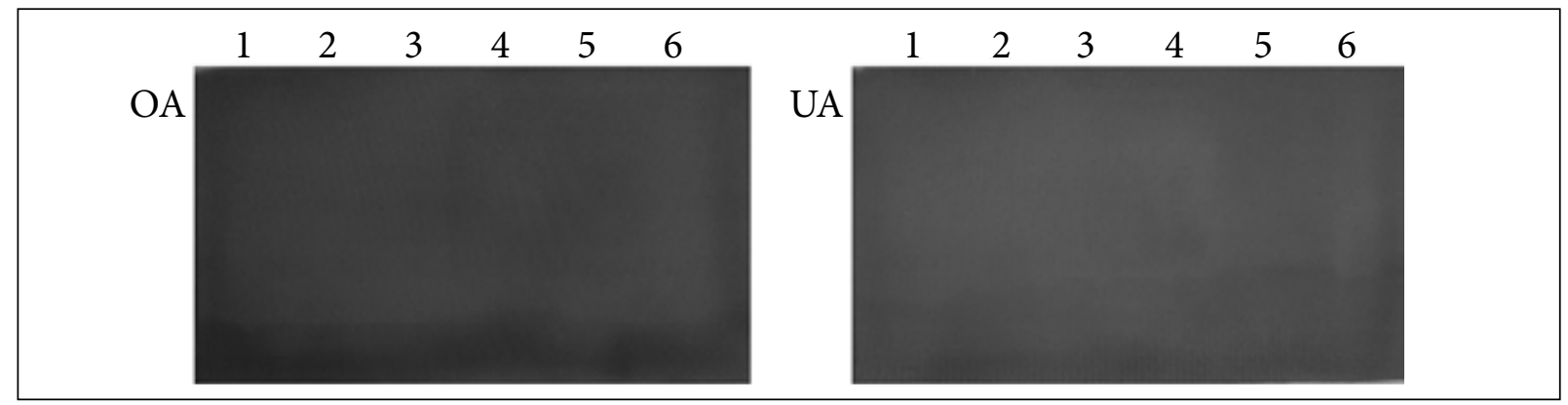

FIGURE 7. SDS-PAGE (gelatine zymography) analysis of metalloproteinases (MMPs) production. Lane 1 - control; lane $2-5 \mu \mathrm{M}$ of the $\mathrm{OA} / \mathrm{UA}$; lane $3-10 \mu \mathrm{M}$ of the $\mathrm{OA} / \mathrm{UA}$; lane $4-25 \mu \mathrm{M}$ of the $\mathrm{OA} / \mathrm{UA}$; lane $5-50 \mu \mathrm{M}$ of the $\mathrm{OA} / \mathrm{UA}$; lane $6-100 \mu \mathrm{M}$ of the $0 \mathrm{~A} / \mathrm{UA}$

totic $\mathrm{Bcl}-2$ protein level by its phosphorylation and degradation, but it does not affect pro-apoptotic $\mathrm{Bcl}-\mathrm{xS}$ or Bax protein amounts. This triterpenoid was also found to activate Fas/FasL pathway and is involved in caspase cascade activation leading directly to apoptotic death of treated cells $[12,13]$. In turn, OA expressed protective effects on normal cells against artificially induced oxidative or inflammatory stress. This compound stabilised mitochondrial membranes or decreased COX-2 and consequently $\mathrm{PGE}_{2}$ production or NADPH oxidase expression [14]. However, the activity of both UA and $\mathrm{OA}$ is dependent on the compound concentration. Lower concentrations of OA expressed mainly anti-proliferative effects, but with its increase pro-apoptotic properties were observed depending on the increase in its concentration $[15,16]$. These reports confirm observations made in our study showing higher activity of UA compared with OA on corneal epithelial cells, but simultaneously the impact of both factors on mitochondrial metabolism was stronger than cellular membrane stability and direct viability of cells.

In our study we found that the higher the concentration of triterpenoids, the higher the $\mathrm{NOx}$ level in culture medium. It is consistent with previously published results indicating that both OA and UA stimulate NO release by normal cells. The process was mainly connected with the increased level of inducible nitric oxide synthase (iNOS) activity. The mechanism of such activity has been designated as taking place through NF- $\mathrm{KB}$ transactivation and calcium-independent mechanisms. Moreover, triterpenoids upregulated the $\mathrm{NO}$ accumulation in 
a dose-dependent manner $[17,18]$. These results are also closely connected and confirm those respecting apoptosis level because NO is a recognised compound that induces apoptosis through changes in the expression of pro-apoptotic proteins like P53 or Bax [18].

However, there are also reports indicating that OA derivatives or UA may inhibit NOS activity and consequently decrease NO level [19, 20]. Nevertheless, we may also suppose that the increased level of NO observed in our study may be linked with the increased apoptotic cell death, uncoupled metabolic pathways, and release of enzymes or nitrates or nitrites deposited in cells into the culture medium.

Metalloproteinases classified as gelatinases (MMP-2 and MMP-9) are very important because they are able to degrade type IV collagen being the most significant element of extracellular matrix and basement membranes [21]. They are generally produced in small amounts but exhibit high proteolytic activity. After quantitative analysis of MMP-2 and MMP-9 levels we observed that OA and UA decrease the amounts of these proteins. These results are consistent with other authors' findings indicating that these pentacyclic terpenoids significantly reduce the expression of metalloproteinases [21-23]. The mechanism of the action was defined as running through inactivation of JNK, Akt, and mTOR pathways or downregulation of NF- $\mathrm{B}$ [2, 22, 23]. When zymography was performed we found that only the highest concentration $(100 \mu \mathrm{M})$ of both OA and UA expressed gelatinolytic activity. Similarly to NOx, it could be the result of the release of proteins from disintegrating cells undergoing apoptosis. This explanation is also supported by the lack of clearly expressed bands of MMPs activity in zymography performed in our study. Instead of this, the whole slot line showed gelatinolytic activity. Therefore, generally low quantities of MMP-2 and MMP-9 in controls and decreased amounts of these proteins after corneal epithelial cell incubation with $\mathrm{OA}$ and UA resulted in a very low, almost undetectable activity of these MMPs measured by zymography.

On the other hand, increased activity of MMP-9 and MMP-2 was observed in lens epithelial cells (LECs) of patients with age-related cataract or in aqueous humour $(\mathrm{AH})$ and uvea in animal models $[6,7,24]$. It suggests that $\mathrm{OA}$ or UA activity decreasing MMP levels in eye tissues might be an interesting alternative in the treatment of ocular diseases. The choice of the compound is also important, and our research indicates that OA may be more useful than UA due to lower concentrations needed to achieve the desired effect. However, further studies are needed to exclude the eventual toxic activities of these triterpenoids or to determine their effective doses for treatment of certain eye tissues.

\section{FUNDING}

This research was financially supported by the Foundation for Polish Science as part of the Parent-Bridge Programme, and co-financed by the European Union from the European Regional Development Fund. The project "The role of tryptophan and its metabolites in physiology and pathology of ocular surface", agreement no. POMOST/2013-7/15, carried out as part of the Innovative Economy Operational Programme ("IE OP”), Priority 1. Research and development of new technologies, Action 1.2. Strengthening the human resources potential of science, Parent-Bridge Programme.

\section{CONFLICT OF INTEREST}

The authors declare no conflict of interest.

\section{REFERENCES}

1. Alvarado HL, Abrego G, Garduño-Ramirez ML, Clares B, Calpena AC, García ML. Design and optimization of oleanolic/ursolic acid-loaded nanoplatforms for ocular anti-inflammatory applications. Nanomed Nanotech Biol Med 2015; 11: 521-530.

2. Huang H-Ch, Huang Ch-Y, L-S Shoei-Yn, Lin J-K. Ursolic acid inhibits IL-1 $\beta$ or TNF- $\alpha$-induced C6 glioma invasion through suppressing the association ZIP/p62 with PKC- $\zeta$ and downregulating the MMP-9 expression. Mol Carcinogen, 2009; 48: 517-531.

3. Córdova C, Gutiérrez B, Martínez-García C, Martín R, Gallego-Munñoz $\mathrm{P}$, Hernández $\mathrm{M}$, et al. Oleanolic acid controls allergic and inflammatory responses in experimental allergic conjunctivitis. PLoS One 9: e91282. doi:10.1371/journal.pone.0091282.

4. Giganti MG, Tresoldi I, Sorge R et al. Physical exercise modulates the level of serum MMP-2 and MMP-9 in patients with breast cancer. Oncol Lett 2016; 12: 2119-2126.

5. Wang Y-F, Peng H-C. MMP-2/-9 and current advances in retinopathy. Int J Ophthalmol 2008; 8: 1640-1643.

6. Alapure BV, Praveen M., Gajjar D, Vasavada AR, Rajkumar S, Johar K. Matrix metalloproteinase- 9 activity in human lens epithelial cells of cortical, posterior subcapsular, and nuclear cataracts. J Cataract Refract Surg 2008; 34: 2063-2067.

7. Cuello C, Wakefield D, Di Girolamo N. Neutrophil accumulation correlates with type IV collagenase/gelatinase activity in endotoxin induced uveitis. Br J Ophthalmol 2002; 86: 290-295.

8. Määttä M, Kari 0 , Tervahartiala $T$ et al. Elevated expression and activation of matrix metalloproteinase 8 in tear fluid in atopic blepharoconjunctivitis. Cornea 2008; 27: 297-301.

9. Bhutto IA, Baba T, Merges C, McLeod DS, Lutty GA. Low nitric oxide synthases (NOSs) in eyes with age-related macular degeneration (AMD). Exp Eye Res 2010; 90: 155-167.

10. Ouyang $H, X u e Y$, Lin $Y$ et al. WNT7A and PAX6 define corneal epithelium homeostasis and pathogenesis. Nature 2014; 511: 358-361. 
11. Lee Y-H, Wang E, Kumar N, Glickman RD. Ursolic acid differentially modulates apoptosis in skin melanoma and retinal pigment epithelial cells exposed to UV-VIS broadband radiation. Apoptosis 2014; 19: 816-828.

12. Yan S-I, Huang Ch-y, Wua S-T, Yin. Oleanolic acid and ursolic acid induce apoptosis in four human liver cancer cell lines. Toxicol In Vitro 2010; 24: 842-848.

13. Zhang Y, Kong Ch, Zeng Y et al. Ursolic acid induces PC-3 cell apoptosis via activation of JNK and inhibition of Akt pathways in vitro. Mol Carcinogen 2010; 49: 374-385.

14. Tsao S-m, Yin M-Ch. Antioxidative and antiinflammatory activities of asiatic acid, glycyrrhizic acid, and oleanolic acid in human bronchial epithelial cells. J Agric Food Chem 2015; 63: 3196-3204.

15. Paik K-J, Jeon S-S, Chung H-Y et al. Induction of differentiation of the cultured rat mammary epithelial cells by triterpene acids. Arch Pharm Res 1998; 21: 398-405.

16. Sánchez-Quesada C, López-Biedma A, Gaforio JJ. Oleanolic acid, a compound present in grapes and olives, protects against genotoxicity in human mammary epithelial cells. Molecules 2015; 20: 13670-13688; doi:10.3390/molecules200813670.

17. Rodriguez-Rodriguez $R$, Stankevicius $E$, Herrera MD et al. Oleanolic acid induces relaxation and calcium-independent release of endothelium-derived nitric oxide. Br J Pharmacol 2008; 155: 535-546.

18. You HJ, Choi ChY, Kim JY, Park SJ, Hahm K-S, Jeong HG. Ursolic acid enhances nitric oxide and tumor necrosis factor- $\alpha$ production via nuclear factor-kB activation in the resting macrophages. FEBS Lett 2001; 509: 156-160.

19. Bhandari P, Patel NK, Gangwal RP, Sangamwar AT, Bhutani KK. Oleanolic acid analogs as NO, TNF- $\alpha$ and IL-1 $\beta$ inhibitors: Synthesis, biological evaluation and docking studies. Bioorg Med Chem Lett 2014; 24: 4114-4119.

20. Shishodia S, Majumdar S, Banerjee S, Aggarwal BB. Ursolic acid inhibits nuclear factor-kB activation induced by carcinogenic agents through suppression of $\mathrm{kB} \alpha$ kinase and $\mathrm{p} 65$ phosphorylation: correlation with down-regulation of cyclooxygenase 2, matrix metalloproteinase 9 , and cyclin D1. Cancer Res 2003; 63: 4375-4383.

21. Huang Ch-Y, Lin Ch-Y, Tsai Ch-W, Yin M-Ch. Inhibition of cell proliferation, invasion and migration by ursolic acid in human lung cancer cell lines. Toxicol In Vitro 2011; 25: 1274-1280.

22. Kim E-S, Moon A. Ursolic acid inhibits the invasive phenotype of SNU-484 human gastric cancer cells. Oncol Lett 2015; 9: 897-902.

23. Yeh Ch-T, Wu Ch-H, Yen G-Ch. Ursolic acid, a naturally occurring triterpenoid, suppresses migration and invasion of human breast cancer cells by modulating c-Jun N-terminal kinase, Akt and mammalian target of rapamycin signaling. Mol Nutr Food Res 2010; 54: 1285-1295.

24. Alapure BV, Praveen MR, Gajjar DU, Vasavada AR, Parmar TJ, Arora Al. Matrix metalloproteinase-2 and -9 activities in the human lens epithelial cells and serum of steroid induced posterior subcapsular cataracts. Mol Vis 2012; 18: 64-73. 